\title{
Cost-effectiveness analysis of the available pneumococcal conjugated vaccines for children under five years in Colombia
}

Jaime E Ordóñez ${ }^{1 *}$ and John Jairo Orozco ${ }^{2}$

\begin{abstract}
Background: Pneumococcal diseases in children under five years are common and preventable. In Colombia there are two pneumococcal conjugate vaccines (PCV) that have proved clinical efficacy. The aim was to estimate the cost-effectiveness of 13-valent PCV (PCV13) and 10-valent PCV (PCV10) in terms of prevention of Invasive Pneumococcal Diseases (IPD), radiologically-confirmed pneumonia, and their related mortality, as well as, acute otitis media (AOM) in a cohort of newborns in Colombia.

Methods: We developed an analytical decision tree model with national data including the distribution of pneumococcal serotypes in Colombia between 2009 and 2013. A simulation of vaccination of $90 \%$ of newborns in Colombia took place with a time horizon of 5 years. The analysis was done from the Colombian health system perspective. Vaccines efficacy parameters were measured as life-years gained (LYG) and avoided morbidity by pneumococcal diseases; they were determined by a systematic review of literature. A health insurance company provided the costs. A probabilistic and a univariate sensitivity analysis for epidemiological, efficacy and cost parameters were done.

Results: After 5 years projection, PCV13 would prevent 437 deaths due to pneumococcal infections versus 321 that would be prevented by PCV10, compared to no vaccination. PCV13 would generate 25396 LYG, and PCV10 would generate 18708 LYG. Medical costs avoided would be US\$ 19479395 for PCV13 and US\$13 703271 for PCV10. Compared to no vaccination, PCV13 and PCV10 were cost-effective, with an incremental cost-effectiveness ratio (ICER) of US\$ 489.26 and US\$ 813.41 per additional LYG, respectively; besides, PCV13 was dominant over PCV10 due to lower costs and better outcomes.

Conclusion: PCV13 is a cost-saving strategy compared with PCV10, as part of a universal coverage vaccination program in Colombian children under one year. PCV13 is expected to lead to a greater decrement in infant mortality from pneumococcal diseases, and a higher cost saving by preventing more pneumococcal diseases compared with PCV10 in a 5 years projection.
\end{abstract}

Keywords: 13-valent pneumococcal vaccine, 10-valent pneumococcal vaccine, Pneumococcal infections, Infant, Cost-benefit analysis, Child mortality

\footnotetext{
* Correspondence: gerencia@hemogroup.com.co

${ }^{1}$ HEMO Group Carrera 25A N 1A Sur-45, piso 5.Torre Médica El Tesoro

Medellín, Medellín, Colombia

Full list of author information is available at the end of the article
}

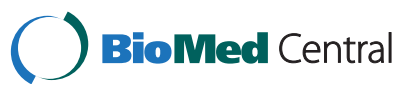

C 2015 Ordóñez and Orozco; licensee BioMed Central. This is an Open Access article distributed under the terms of the Creative Commons Attribution License (http://creativecommons.org/licenses/by/4.0), which permits unrestricted use, distribution, and reproduction in any medium, provided the original work is properly credited. The Creative Commons Public Domain Dedication waiver (http://creativecommons.org/publicdomain/zero/1.0/) applies to the data made available in this article, unless otherwise stated. 


\section{Introduction}

The diseases produced by Streptococcus Pneumoniae (SP), such as pneumonia, sepsis (including bacteremia), meningitis and acute otitis media (AOM) are a severe public health problem. Annually, 2 million children die worldwide due to pneumonia, which is more than those due to AIDS, malaria and measles together [1]. In order to reduce the mortality rate in children younger than 5 years by two thirds, one of the Millennium Development Goals (MDG) [2] included strategies as pneumococcal vaccination. [3].

In 2000 was introduced the first pneumococcal conjugated vaccine. This vaccine was composed of purified capsular polysaccharides of seven pneumococcus serotypes (4, $6 \mathrm{~B}, 9 \mathrm{~V}, 14,18 \mathrm{C}, 19 \mathrm{~F}$ and $23 \mathrm{~F}$ ) conjugated to a diphteria protein $\left(\mathrm{CRM}_{197}\right)$, and demonstrated its clinical efficacy and effectiveness (PCV-7) [4-6]. A health economics analysis concluded that PCV7 would prevent 678,000 AOM cases and 175,000 pneumonia cases due to SP by year in Latin America and the Caribbean region [7]. In Uruguay, PCV7 was found highly cost-effective and recommendable for countries with a similar distribution of serotypes [8].

In 2010 it was launched, a 10-valent conjugate vaccine (PCV-10), that add the three serotypes 1, 5 and $7 \mathrm{~F}$. Eight of the ten serotypes in PCV10 are conjugated to the D protein of non typeable Haemophilus influenza, of the remaining two, one to tetanus toxoid and one to diphtheria toxoid. Later, the 13-valent pneumococcal conjugate vaccine (PCV13) was launched with the three additional serotypes 3,6A and 19A. All 13 serotypes in PCV13 are conjugated to $\mathrm{CRM}_{197}$, the same protein carrier used for PCV7.

Currently, in Colombia there are two available technologies to prevent pneumococcal diseases in children younger than 5 years, PCV10 and PCV13. Due to the difference in terms of the effectiveness and costs of the vaccines, it is necessary to estimate the cost-effectiveness of both strategies in order to allow an informed decision taking. Our objective is to estimate the cost-effectiveness ratio between PCV13 and PCV10 as part of an infant vaccination program, considering the current pneumococcal serotypes distribution in Colombia.

\section{Methods}

An analytical decision tree model was constructed (Figure 1) with local data on the prevalence of Invasive Pneumococcal Disease (IPD) (meningitis and sepsis, including bacteremia), pneumococcal AOM and radiologically-confirmed pneumonia. The model was developed by the authors and simulates a cohort of newborns in Colombia. The model assumed that at the beginning, individuals would be vaccinated with PCV13 or PCV10 or would not be vaccinated. Mortality rates from IPD and pneumonia were considered to calculate deaths avoided. Costs of medical treatments were calculated based on the site of healthcare, it means, inpatient or outpatient.

To determine epidemiologic distribution of SP serotypes found in children younger than 5 years in Colombia between 2009 and 2013, we used the data of Regional Vaccine System (SIREVA II; by their acronym in Spanish), which reports serotypes of all isolates made in Colombia by IPD. A systematic review was done, in order to determine the efficacy of both vaccines, adjusted to the distribution of pneumococcal serotypes. This research does not involve any human subject, and secondary sources of information such as scientific papers and bills payment were used.

\section{Model}

The cohort to evaluate morbidity children was born in Colombia in 2012; with a 5 follow up years. In order to calculate the life-years gained (LYG), the life expectancy during the period 2010-2015 for both sexes was assumed [9]. The reason for using children born in 2012 as the cohort group rather than the population projections made by the National Administrative Department of Statistics (DANE; by their acronym in Spanish) for later years; is that the results of those projections are $20 \%$ below of the real-life data.

The international health agencies and the local regulatory agency (INVIMA for Colombia) have approved the use of both vaccines: PCV10 and PCV13, based on comparison of immunologic response to PCV7 to common serotypes. Thus, PCV7 is the basis for the clinical efficacy and is the support to approve other conjugated vaccines [10].

Since PCV13 and PCV10 have regulatory approval to prevent pneumococcal diseases caused by the serotypes included in the vaccines, the probabilities of becoming ill by these serotypes were adjusted according to the SIREVA II, which reports the serotypes that cause IPD and are isolated in Colombia [11].

In order to depict the risk for clinical outcomes, pneumococcal sepsis, pneumococcal meningitis, radiologicallyconfirmed pneumonia and pneumococcal AOM, a decision analytical tree model was used [4-8]. To estimate avoided deaths, the probability of death from pneumonia, meningitis and sepsis was considered. A discount rate of $3 \%$ for costs and effects was applied, according to the recommendation of the World Health Organization (WHO) [12]. The analysis was done from the Colombian health system perspective.

Three alternatives were considered: not vaccination, vaccination with PCV10 or vaccination with PCV13. The direct efficacy of the vaccines was considered during the first 5 years of life. The cost-effectiveness analysis was performed among the three alternatives in terms of each disease related morbidity cases and deaths, as well as, life-years gained (LYG). 


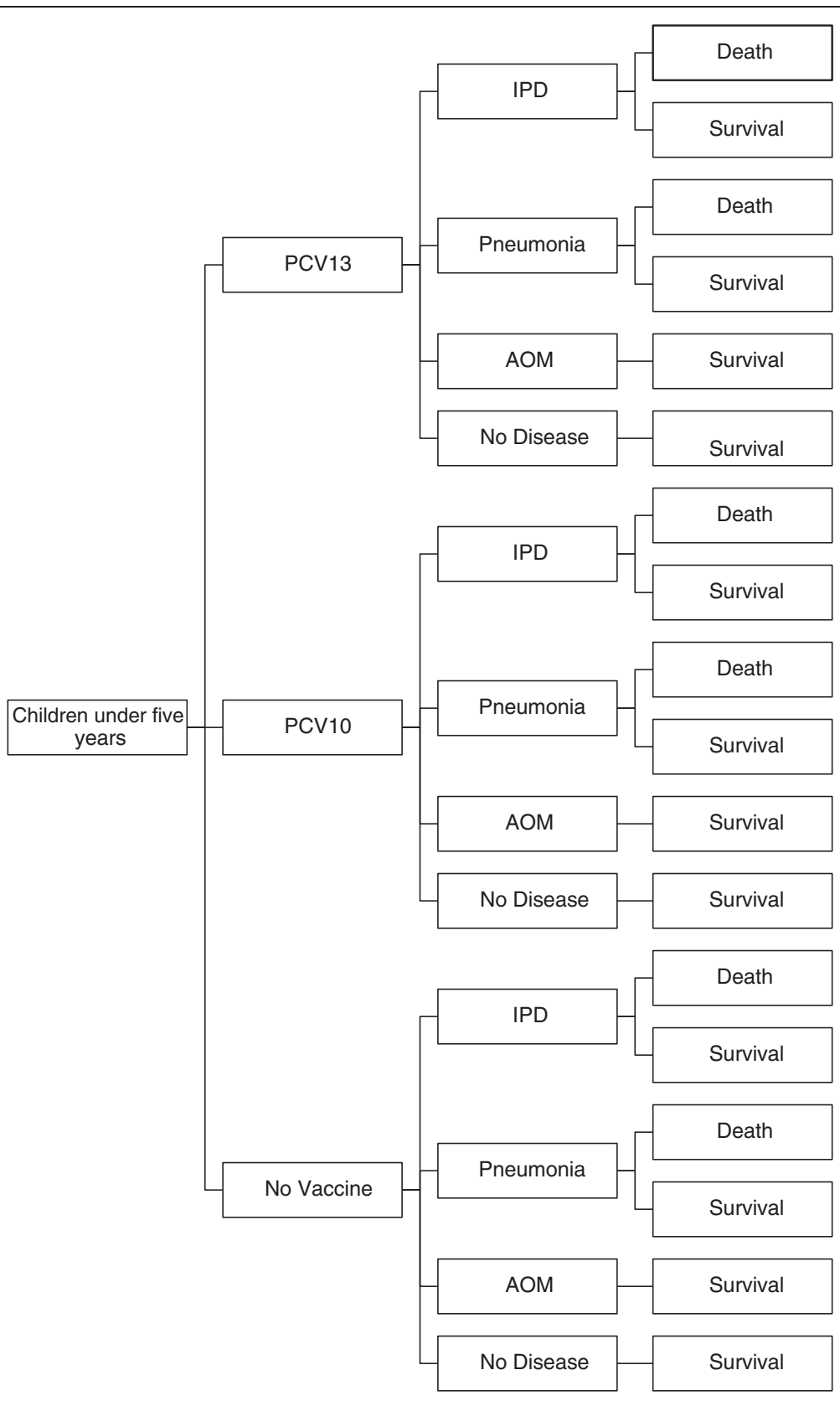

Figure 1 Decision tree for the cost-effectiveness analysis on vaccinating with PCV13, PCV10 or not vaccinating in a cohort of newborns in Colombia.

\section{Epidemiologic parameters}

In order to determine the likelihood of IPD, the incidence was calculated using a local study performed in Colombian population [13]. The likelihood of developing radiologically-confirmed pneumonia was calculated [14] based on population indicators of pneumonia like the discharge diagnosis in children younger than 5 years in Medellin during 2009 [15]. This was adjusted according to the proportion of children with a clinical diagnosis of pneumonia that could be confirmed radiologically [13].

The incidence of AOM was estimated only for pneumococcal AOM according with the indications approved by the INVIMA. The population indicators of AOM used were the discharge diagnosis from the emergency room or outpatient visits in children younger than 5 years in Medellin during 2009 [15]. This was adjusted according to the proportion of children with a 
clinical diagnosis of AOM who had pneumococcus as the confirmed etiologic agent [17].

The probability of mortality due to IPD was $37 \%$ and to pneumonia $3 \%$, it was determined by assuming the values reported on a cost-effectiveness study of PCV7 performed in Colombian children during 2010 [18]. Vaccination coverage of $90 \%$ was assumed, in line with the assumptions by other authors [18]. A herd effect of $42 \%$ was assumed based on the decline rate of IPD in infants 0 to 60 days old that were not vaccinated with PCV7 who lived in the same regions of the vaccinated children [20]. Thus, if $10 \%$ of children are not vaccinated, the protecting effect of the vaccine would also benefit $4.2 \%$ of this $10 \%$ (Table 1 ).

\section{Measurement of effectiveness}

Vaccines effectiveness was assessed by a systematic review The following databases were used: EBSCO Host, EMBASE, OVID, PLoS, PubMed, Science Direct, Springer, Wiley InterScience, Wolters Kluwer Health and Randomized Controlled Essays were considered. The MeSH terms used in the search, in different combinations, were: pneumococcal vaccines, streptococcus pneumonia, sepsis, pneumococcal meningitis, pneumonia, and otitis media.

The repeated references were removed, as well as those with polysaccharide vaccines; with adults with immunodeficiencies; with senior adults; with a shorter than six months follow up period and those that only evaluated immunogenicity without considering clinical results.

PCV7 was the first conjugated vaccine with published efficacy studies for IPD; PCV10 and PCV13 were approved based on immunogenicity comparisons with PCV7. One RCT determined the efficacy of PCV7 for preventing meningitis and sepsis in children under 5 years [5]. The PCV13 efficacy for radiologically-confirmed pneumonia was taken from a study made with PCV7 in children under than 5 years [21].

The PCV10 efficacy for radiologically-confirmed pneumonia and IPD was taken from the COMPAS study, a multicenter study in which Colombia participated [22].

The effectiveness of vaccines against AOM, were adjusted according to the prevalence of the pneumococcus serotypes in Colombia. Based on their clinical effectiveness, this was adjusted according to the circulating serotypes in the country and that are contained in each vaccine. We did that adjustment because a vaccine could have a high effectiveness but against serotypes with a low prevalence in our country.

In the case of PCV13, we took PCV7 efficacy to prevent pneumococcal AOM (83\% (IC 95\%: 75\% - 91\%)) [23] caused by serotypes contained in PCV7. To determine the efficacy of PCV10 to prevent pneumococcal AOM, we assumed it reported on a RCT that evaluated an 11-valent precursor to PCV10 (52.6\% (IC 95\%: 35.0\% - 65.5\%)) [16]. Based on the reports by SIREVAII between 2009 and 2013, PCV10 covers $61.6 \%$ and PCV13 covers $82.0 \%$ of pneumococcus serotypes causing invasive disease in Colombia in children under than 5 years [11]. It means, PCV13 efficacy was adjusted by $82.0 \%$ and PCV10 efficacy was adjusted by $61.6 \%$ (Table 1).

\section{Economical parameters}

The direct costs include the costs of the PCV10 (Synflorix ${ }^{\circ}$ ) and PCV13 (Prevenar $13^{\circ}$ ) vaccines and the application of three doses. The values used are the ones recommended by the Pan American Health Organization for 2014 [24]. Medical costs associated with the treatment of disease were assumed to be a lower value to pay for each case prevented (Table 1).

The database of a national health insurance company which has more than 2 million members (which ensures the representativeness of the population), was used to determine the costs for treating sepsis, meningitis and pneumonia in children younger than 5 years in Colombia. The costs were determined based on the value paid by the health insurance companies to the hospitals and it comprises all of the services offered during the hospitalization including hospital visits, diagnostic aids, antibiotic treatments and other necessary services used for the recovery of the patient until discharge. The rates for all these services are based on a government reimbursement manual for national application. In 2013, this health insurance company reported a total of 72 children younger than 5 years with sepsis, 36 with meningitis and 541 with pneumonia. These values were adjusted with the Consumer's Price Index reported by the DANE for 2013: 1.94\% [25]. An exchange rate of COP 1959 was assumed for the calculation in dollars, since it was the average exchange rate for the first six months of 2014.

To calculate the cost of care for an episode of AOM, two clinical guidelines [26,27] that propose the same antibiotic treatment (amoxicillin $90 \mathrm{mg} / \mathrm{kg} /$ day) were considered. The cost of a $90 \mathrm{ml}$ acetaminophen bottle was added to this treatment regimen as well as the cost of two outpatient visits, based on the values of the national tariff manual updated to 2014 [28] (Table 2).

It was considered that an alternative is cost-effective if the cost per additional unit of effectiveness (LYG) is less than 3 Colombian GDP per capita (US\$ 24,075 for 2013), and highly cost-effective if less than 1 Colombian GDP per capita (US\$ 8025 for 2013) [29].

\section{Incremental cost-effectiveness analysis}

When a technology is more cost-effective than other but at the same time is costlier, it is necessary an economic decision criteria. The question in this case would be how much additional costs have to be paid for the additional 
Table 1 Demographic and epidemiologic parameters of the probability of developing pneumococcal disease and the efficacy of PCV13 and PCV10 and cost of care in Colombian children younger than 5 years, 2014

\begin{tabular}{|c|c|c|c|c|c|}
\hline \multicolumn{2}{|l|}{ Parameters } & \multicolumn{2}{|l|}{ Mean value } & Data distribution & Reference \\
\hline \multicolumn{6}{|l|}{ Demographic } \\
\hline \multicolumn{2}{|l|}{ Newborns in 2012} & \multicolumn{2}{|l|}{676835} & Does not vary & [19] \\
\hline \multicolumn{2}{|l|}{ Life expectancy } & \multicolumn{2}{|l|}{73,78} & Does not vary & [9] \\
\hline \multicolumn{2}{|l|}{ Discount rate } & \multicolumn{2}{|l|}{$3 \%$} & $2 \%-5 \%$ & [13] \\
\hline \multicolumn{6}{|l|}{ Epidemiologic } \\
\hline \multicolumn{2}{|l|}{ Pneumococcal sepsis probability } & \multicolumn{2}{|l|}{0,000184} & Beta & [13] \\
\hline \multicolumn{2}{|l|}{ Pneumococcal meningitis probability } & \multicolumn{2}{|l|}{0,000037} & Beta & [13] \\
\hline \multicolumn{2}{|c|}{ Radiographically confirmed pneumonia probability (a) } & \multicolumn{2}{|l|}{0,007441} & Beta & {$[13,15]$} \\
\hline \multicolumn{2}{|l|}{ Pneumococcal AOM probability (b) } & \multicolumn{2}{|l|}{0,031171} & Beta & {$[15,17]$} \\
\hline \multicolumn{2}{|l|}{ PID mortality (meningitis, sepsis) } & \multicolumn{2}{|l|}{$37 \%$} & Beta & [18] \\
\hline \multicolumn{2}{|l|}{ Pneumonia mortality } & \multicolumn{2}{|l|}{$3 \%$} & Beta & [18] \\
\hline \multicolumn{2}{|l|}{ Vaccination coverage } & \multicolumn{2}{|l|}{$90 \%$} & Beta & Assumption \\
\hline \multicolumn{2}{|l|}{ Herd effect } & \multicolumn{2}{|l|}{$42 \%$} & & [20] \\
\hline \multirow[t]{2}{*}{ Parameter } & \multirow[t]{2}{*}{ Mean value } & \multicolumn{2}{|l|}{ Range } & Data distribution & References \\
\hline & & Inferior limit & Superior limit & & \\
\hline \multicolumn{6}{|l|}{ Efficacy of intervention } \\
\hline Meningitis, sepsis PCV10 & $65,0 \%$ & $11,1 \%$ & $86,2 \%$ & Beta & [22] \\
\hline Radiographically confirmed pneumonia PCV10 & $22,4 \%$ & $5,7 \%$ & $36,1 \%$ & Beta & [22] \\
\hline AOM due to S. pneumoniae PCV10 (c) & $32,4 \%$ & $21,6 \%$ & $40,4 \%$ & Beta & {$[11,16]$} \\
\hline Meningitis, sepsis PCV13 & $89,1 \%$ & $73,7 \%$ & $95,6 \%$ & Beta & [5] \\
\hline Radiographically confirmed pneumonia PCV13 & $30,3 \%$ & $10,7 \%$ & $45,7 \%$ & Beta & [21] \\
\hline AOM due to S. pneumoniae PCV13 (d) & $68,1 \%$ & $61,5 \%$ & $74,6 \%$ & Beta & {$[11,23]$} \\
\hline \multicolumn{6}{|l|}{ Vaccine costs } \\
\hline Cost of PCV10 & $\$ 14,12$ & $\$ 12,71$ & $\$ 15,53$ & Gama & [24] \\
\hline Cost of PCV13 & $\$ 15,68$ & $\$ 14,11$ & $\$ 17,25$ & Gama & [24] \\
\hline Administration cost (per dose) & $\$ 1,00$ & $\$ 0,9$ & $\$ 1,10$ & Gama & Assumption \\
\hline Cost of sepsis & $\$ 8192$ & $\$ 292$ & $\$ 104535$ & Gama & Health insurance company \\
\hline Cost of meningitis & $\$ 11595$ & $\$ 1165$ & $\$ 54891$ & Gama & Health insurance company \\
\hline Cost of pneumonia & $\$ 1854$ & $\$ 306$ & $\$ 40812$ & Gama & Health insurance company \\
\hline Cost of $\mathrm{AOM}$ & $\$ 40$ & $\$ 36$ & $\$ 44$ & Gama & {$[26,27]$} \\
\hline
\end{tabular}

a. Incidence of pneumonia in Medellin in 2009, adjusted to the proportion of pneumonia cases confirmed radiographically (Benavides et al [13]).

b. Incidence of AOM in Medellin in 2009, adjusted to the proportion of AOM cases due to pneumococcus (Sierra et al [17]).

c. Clinical efficacy of PCV11 for preventing AOM due to S. pneumoniae, adjusted according to the proportional frequency of serotypes circulating in Colombia between 2009 and 2012, contained in PCV10.

d. Clinical efficacy of PCV7 for preventing AOM due to S. pneumoniae, adjusted according to the proportional frequency of serotypes circulating in Colombia between 2009 and 2012, contained in PCV13.

effectiveness. This is known as the Incremental CostEffectiveness Ratio (ICER). In other words, what was the incremental cost for PCV13 compared to the PCV10 and not vaccination related to the corresponding incremental effectiveness?

\section{Sensitivity analysis}

In order to assess the robustness of the model, as well as the sensitivity of the ICER to the parameters of the main variables, univariate and probabilistic sensitivity analysis were done. For the first case, the extreme values of the ranges were used to test the ICER results. For the probabilistic sensitivity analysis, a one thousand iterations Montecarlo simulation was performed. Beta distribution was used for clinical parameters and gamma distribution for the avoided medical costs and vaccine costs. The beta and gamma parameters were calculated with the respectively means and standard deviations of each variable. 
Table 2 LYG, Total costs and ICER for PCV13, PCV10 and no vaccination in Colombian children younger than 5 years, 2014

\begin{tabular}{llll}
\hline & $\begin{array}{l}\text { No } \\
\text { vaccine }\end{array}$ & PCV10 & PCV13 \\
\hline $\begin{array}{l}\text { Total discounted LYG } \\
\text { Discounted medical costs } \\
\text { avoided }\end{array}$ & 0 & 18708 & 25396 \\
Vaccine costs* & 0 & $\$-13703271$ & $\$-19479395$ \\
Total costs & 0 & $\$ 28920564$ & $\$ 31904432$ \\
$\begin{array}{l}\text { C/E Prevented cases } \\
\text { (per additional LYG) }\end{array}$ & & $\$ 15217293$ & $\$ 12425037$ \\
$\begin{array}{l}\text { Incremental analysis } \\
\text { ICER No Vaccine vs. PCV10 }\end{array}$ & $\$ 813.41$ & & $\$ 489.26$ \\
ICER PCV10 vs. PCV13 & $\$-417.53$ & & \\
\hline
\end{tabular}

*Included administration costs.

LYG: Life Years Gained.

C/E: Cost-effectiveness ratio.

Acceptability curves and cost-effectiveness plane was included for measurement uncertainty reflected by the model.

\section{Results}

\section{Effectiveness}

After 5 years follow up projection, compared to no vaccination, PCV13 would prevent 66005 pneumococcal AOM cases and 437 deaths due to pneumococcal infections and PCV10 would prevent 31401 pneumococcal AOM cases and 321 deaths due to pneumococcal infections. In the same way, PCV13 would generate 25396 LYG and PCV10 would generate 18708 LYG (Table 3).

\section{Costs}

Although the cost to vaccinate $90 \%$ of children was higher for PCV13 compared to PCV 10 (US\$ 31904432 versus US\$ 28920 564), this price is compensated by the greater savings obtained by the avoided cases with PCV13 compared to PCV10. Medical costs avoided were US\$ 19479395 for PCV13 and US\$ 13703271 for PCV10.

\section{Cost-effectiveness of the pneumococcal conjugate vaccines}

PCV13 showed a better cost-effectiveness ratio for the cases of meningitis, sepsis, radiologically-confirmed pneumonia and AOM prevented. Cost-effectiveness ratio to prevent pneumococcal AOM cases was US\$ 446.15 with PCV13 and US\$ 883.79 with PCV10. Compared to no vaccination, the ICER of PCV13 US\$ 489.26 per LYG, while the ICER of PCV10 was US\$ 813.44 per LYG. With a greater effectiveness and lower costs, PCV13 was dominant to PCV10 (Table 2).
Table 3 Prevented cases of sepsis, meningitis, pneumococcal AOM and radiographically confirmed pneumonia; as well as prevented deaths per year and life years gained, when applying PCV13 and PCV10 in Colombian children younger than 5 years, 2014

\begin{tabular}{lll}
\hline Parameter & PCV13 & PCV10 \\
Prevented cases & 510 & 372 \\
\hline Pneumococcal sepsis & 103 & 75 \\
Pneumococcal meningitis & 7011 & 5183 \\
RX confirmed pneumonia & 66005 & 31401 \\
Pneumococcal AOM & & 138 \\
Prevented deaths & 189 & 28 \\
Pneumococcal sepsis & 38 & 155 \\
Pneumococcal meningitis & 210 & 321 \\
RX confirmed pneumonia & 437 & 816 \\
All causes & & 13832 \\
Life years gained & 5565 & 18708 \\
Pneumococcal sepsis & 1119 & \\
Pneumococcal meningitis & 18712 & 396 \\
RX confirmed pneumonia & 25396 \\
All causes & &
\end{tabular}

\section{Univariate sensitivity analysis}

For the univariate sensitivity analysis, the high and low ranges of the discount rate, vaccines' costs, treatments costs and effectiveness of the vaccines were tested in the univariate analysis. It allows to observe how sensible was the ICERs to this changes. PCV13 was dominant over PCV10 in ten of 12 variations (Table 4 and Figure 2). Therefore, the ICER result in the univariate sensitivity analysis shows a very robust model.

\section{Probabilistic sensitivity analysis}

The probabilistic sensitivity analysis showed the robustness of results of the model. Most of the simulations of PCV10 and PCV13 overlapped each other, and were located in the $\mathrm{NE}$ and SE quadrants relative to not vaccinating, supporting that both options were more effective than not vaccinating. PCV13 offered more LYG than PCV10 and a lesser cost. In $81 \%$ of the 1000 simulations made by the model, PCV13 is cost-effective compared to PCV10 (Figure 3).

\section{Acceptability curves}

The acceptability curves allow to know what is the likelihood for a strategy to be chosen, compared with the another one. For a willingness to pay of 1 GDP per Capita for Colombia, PCV13 has a probability of $78 \%$ to be chosen, meaning this is strategy is highly cost-effective. In the same way, for a willingness to pay of 3 GDP, PCV13 has a probability of $81 \%$ to be chosen and PCV10 has a probability of 19\% (Figure 4). 
Table 4 Univariate sensitivity analysis of ICER results of PCV13 vs PCV10 vs no vaccination in Colombian children younger than 5 years, 2014

\begin{tabular}{|c|c|c|c|c|c|c|c|c|c|}
\hline & \multicolumn{3}{|l|}{ Base case } & \multicolumn{3}{|l|}{ Lowest value } & \multicolumn{3}{|l|}{ Highest value } \\
\hline & \multirow[t]{2}{*}{ Base case value } & \multicolumn{2}{|l|}{ ICER } & \multirow[t]{2}{*}{ Value to prove } & \multicolumn{2}{|l|}{ ICER } & \multirow[t]{2}{*}{ Value to prove } & \multicolumn{2}{|l|}{ ICER } \\
\hline & & $\begin{array}{l}\text { NV vs } \\
\text { PCV10 }\end{array}$ & $\begin{array}{l}\text { PCV10 vs } \\
\text { PCV13 }\end{array}$ & & $\begin{array}{l}\text { NV vs } \\
\text { PCV10 }\end{array}$ & $\begin{array}{l}\text { PCV10 vs } \\
\text { PCV13 }\end{array}$ & & $\begin{array}{l}\text { NV vs } \\
\text { PCV10 }\end{array}$ & $\begin{array}{l}\text { PCV } 10 \text { vs } \\
\text { PCV13 }\end{array}$ \\
\hline Discount rate & $3 \%$ & 813,41 & $-417,53$ & $2 \%$ & 612,22 & $-338,43$ & $5 \%$ & $1.288,37$ & $-572,40$ \\
\hline \multicolumn{10}{|c|}{ Vaccine costs (US\$) } \\
\hline PCV10 & 45,36 & 813,41 & $-417,53$ & 41,12 & 669,04 & $-13,68$ & 49,60 & 957,77 & $-821,39$ \\
\hline PCV13 & 50,04 & 813,41 & $-417,53$ & 45,34 & 813,41 & $-866,01$ & 54,74 & 813,41 & $-30,94$ \\
\hline \multicolumn{10}{|c|}{ Medical costs (US\$) } \\
\hline Avoided cases & Mean values & 813,41 & $-417,53$ & Mean values & $1.401,61$ & $-185,47$ & Mean values & $11.082,66$ & $-12.268,58$ \\
\hline \multicolumn{10}{|c|}{ PCV10 effectiveness } \\
\hline Sepsis & 0,6500 & 813,41 & $-417,53$ & 0,1110 & $5.804,26$ & $-609,93$ & 0,8620 & 288,94 & $-1.223,03^{*}$ \\
\hline Meningitis & 0,6500 & & & 0,1110 & & & 0,8620 & & \\
\hline Pneumonia & 0,2240 & & & 0,0570 & & & 0,3610 & & \\
\hline OMA & 0,3240 & & & 0,2160 & & & 0,4040 & & \\
\hline \multicolumn{10}{|c|}{ PCV 13 effectiveness } \\
\hline Sepsis & 0,8910 & 813,41 & $-417,53$ & 0,7370 & 813,41 & $-923,48^{*}$ & 0,9630 & 813,41 & $-568,52$ \\
\hline Meningitis & 0,8910 & & & 0,7370 & & & 0,9630 & & \\
\hline Pneumonia & 0,3030 & & & 0,1070 & & & 0,4468 & & \\
\hline OMA & 0,6810 & & & 0,6150 & & & 0,7944 & & \\
\hline
\end{tabular}

PCV13: 13-valent pneumococcal conjugate vaccine.

PCV10: 10-valent pneumococcal conjugate vaccine.

NV: no vaccination

*In these two cases, PCV10 is dominant.

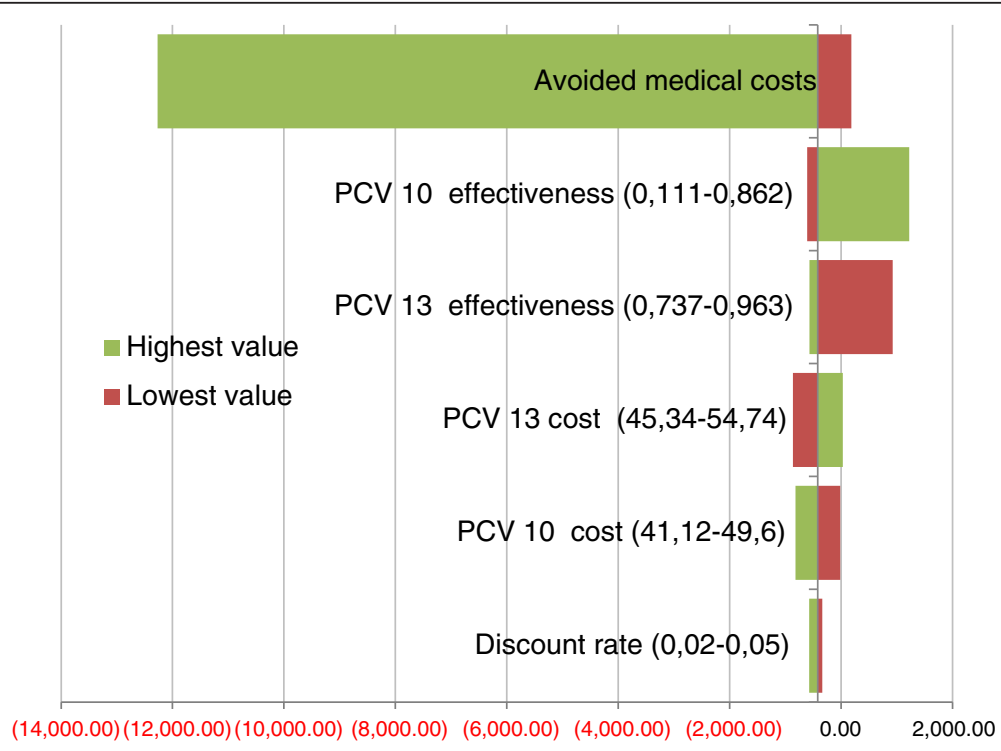

Figure 2 Tornado diagram of PCV13 vs. PCV10 to prevent pneumococcal diseases in a cohort of Colombian children, 2014. 


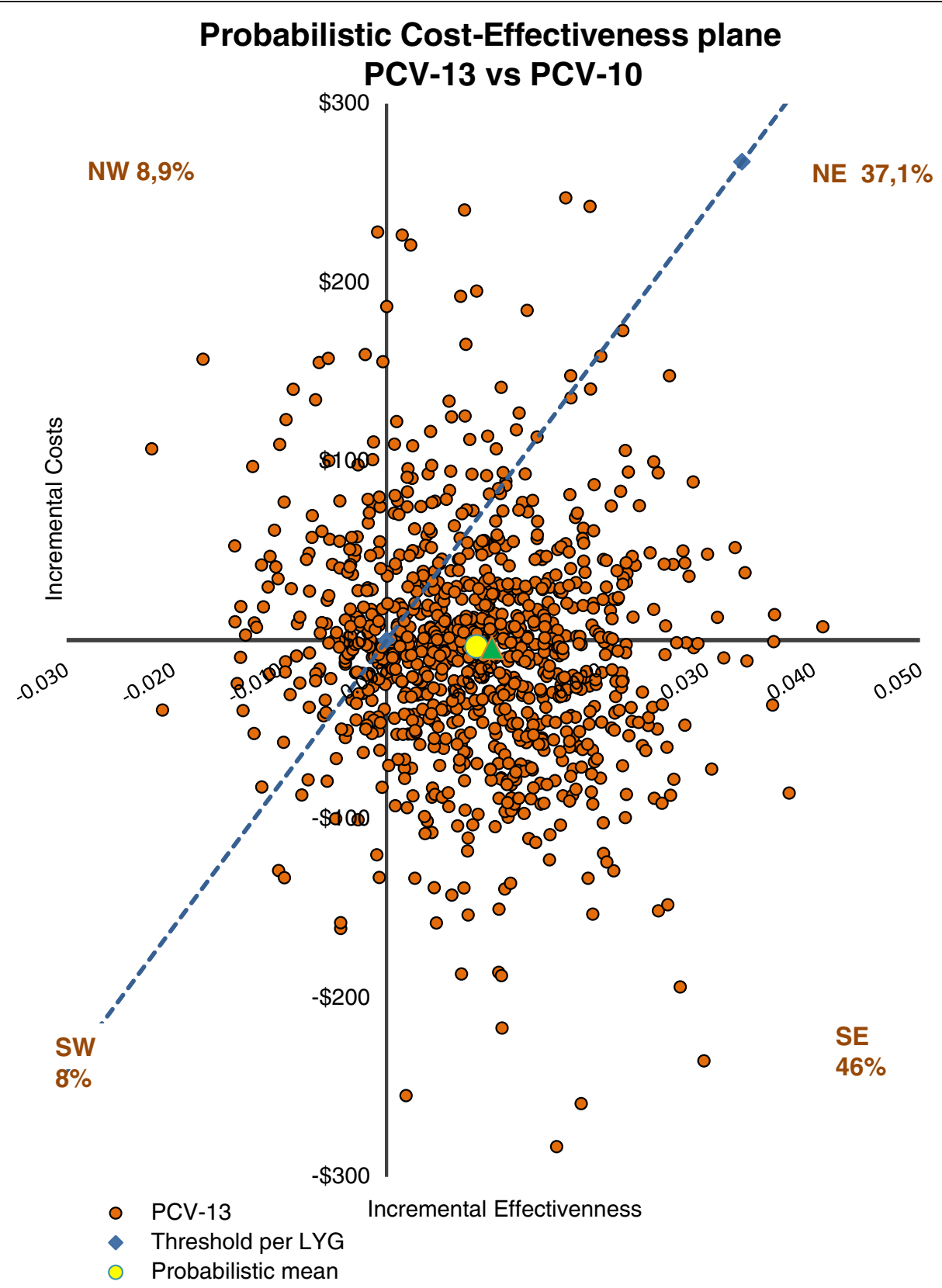

Figure 3 Probabilistic cost-effectiveness plane in which the LYG are plotted versus the costs for PCV13 and PCV10 in a cohort of Colombian newborns, 2014.

\section{Discussion}

This cost-effectiveness analysis has identified the clinical and economical results of PCV13 and PCV10. From the Colombian health system perspective both strategies are superior to no vaccination in terms of prevented cases, ICER, LYG and prevented deaths.

PCV13 presented more benefits in regards to prevented cases and deaths due to IPD, radiologically-confirmed pneumonia and AOM. PCV13 is the dominant option over
PCV10 since it avoids more deaths, more LYG are obtained and fewer resources are consumed due to greater reduction in disease.

There is no doubt that vaccination with pneumococcal vaccines from 2000 has been a positive impact on public health to prevent pneumococcal diseases, particularly mortality related with $S$. pneumoniae. Our main contribution to this discussion is to generate valid information that allows decision makers in Colombia, to identify 


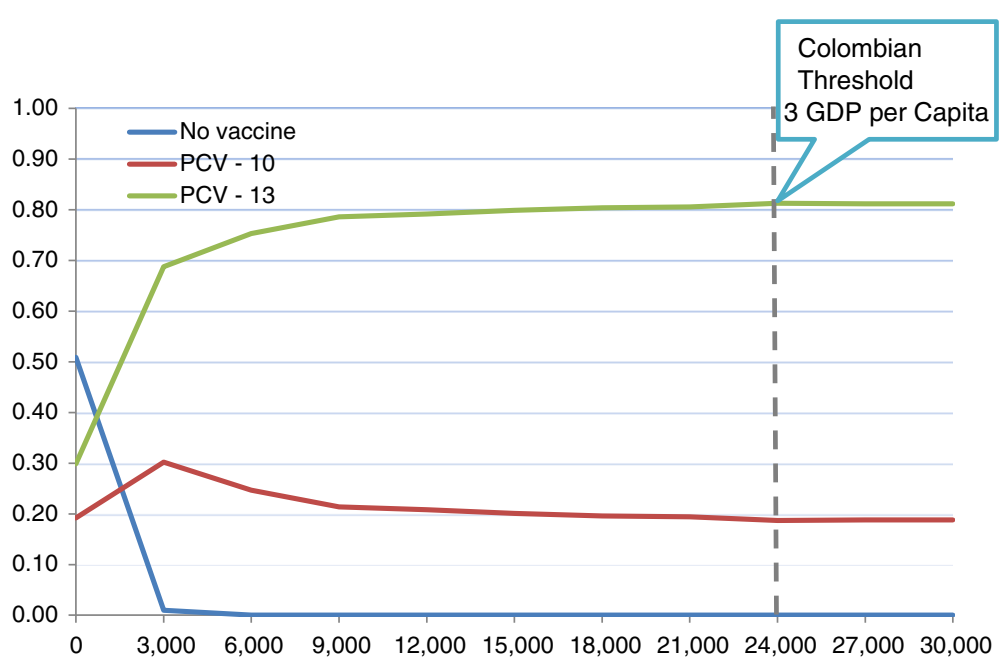

Figure 4 Cost-Effectiveness Acceptability curves of PCV13 vs. PCV10 vs. no vaccine to prevent pneumococcal diseases in a cohort of Colombian children, 2014.

which of the strategies available is more cost-effective to carry out an immunization program with pneumococcal vaccines in our country.

On 2007 PCV7 was included in the Colombian Plan of Immunization; initially for high risk population and later for low weight newborns and the ten departments with the highest mortality rates [30]. Since 2010, was implemented the universal vaccination with PCV13 based on the additional coverage of six serotypes increasing the coverage up to approximately $60 \%$ of the national territory. In September 2011 the Colombian Plan of Immunization replaced the PCV13 with PCV10. This change was after the publication of a cost-effectiveness study that evaluated PCV7, PCV10 and PCV13 [19]. There was a model that assumed that PCV10 would have an excess impact on preventing AOM due to all causes, even though PCV13 would prevent more cases of pneumonia, IPD and deaths [18].

The main differences of this model with the latest cost-effectiveness study published on the subject in the country [18] are (1) the assumption that PCV10 is effective against non-typeable $H$. influenza, (2) the AOM prevalence parameter which was not adjusted specifically for pneumococcus, (3) the medical costs source is not local and (4) the time periods analyzed in both studies were different (2007-2009 vs. 2009-2013).

The higher number of IPD and pneumonia cases avoided with PCV13 shown in both studies was based mainly on the better coverage of the circulating serotypes in Colombia by PCV13; serotype coverage is $33 \%$ higher than the coverage by PCV10: $82.0 \%$ vs. $61.6 \%[11]$.

Although the cost of every dose of PCV13 is US\$ 1.56 higher than PCV10, the largest IPD and AOM cases avoided with PCV13 allows the latter to be a dominant strategy, because the savings generated by direct costs of treatment of cases avoided are greater than the costs difference in an immunization program between both of them strategies. Even though the analysis perspective was from a Colombian health system, it could be inferred that from a societal perspective the results would be similar, because issues related with both of patients and caregivers, such as travel times to medical appointments or time to care sick children, will be greater in the strategy that avoided fewer IPD and AOM cases.

The results of this research coincide with another ten cost-effectiveness analysis on PCV13 performed in different countries [31-40]. All these conclude that PCV13 prevents more cases and more deaths due to pneumococcal diseases than PCV10 and thus is a better alternative in terms of costs compared to PCV10. Strutton et al [31] conclude that a pediatric national immunization program with PCV13 would eliminate $31.7 \%$ of IPD in Germany, $46.4 \%$ in Greece, and 33.8\% in the Netherlands, and it was a cost saving strategy, compared with PCV7 and PCV10. Earnshaw et al point out that an immunization program with PCV13 is a cost-saving strategy in Canada because it provides substantial public health and economic benefits versus to PCV10 [33].

Furthermore, Newall et al assert that the high proportion of current IPD caused by serotype 19A (included in PCV13 but not in PCV10) may be an overriding factor in the design of vaccination policies in Australia [32]. In the same way, isolates in Colombia of serotype 19A have increased seven times, and serotype 3 have increased four times, between 2009 and 2013 compared with the period between 1994 and 2008 [11].

In the same way, all these health economic evaluations [31-40] used analytical decision tree models as the best 
option to explain the relationship between the natural history of pneumococcal diseases and PCV, because these are acute diseases and their probability of recurring events is low. In fact, the effectiveness of both vaccines used in this model is calculated only against the serotypes included in each vaccine and we did not considered cross immunogenicity. Although there is the likelihood to suffer disabilities in patients with meningitis, i.e. deafness, our main outcomes were mortality and life years gained, since this is a costeffectiveness analysis, not a cost-utility analysis.

In Latin America there are two important studies with similar results, one in Mexico and another one in Uruguay. The first one concludes that immunization with PCV7, PCV10 or PCV13 would be cost-saving interventions, however, health outcomes and savings of the strategy with PCV13 are greater than those estimated for PCV7 and PCV10 [37]. The later concluded that there was a significant decline on incidence of hospitalizations for consolidated pneumonia in children younger than 2 years of age, related with a vaccination schedule of $2+1$ with PCV13 [40].

Five research studies have concluded that PCV13 avoids more deaths due to pneumococcal diseases than PCV10, but no more cases of overall disease [18,37,41-43]. The results of these differ from the above studies because they assume that PCV10 is effective in preventing AOM due to $S$. pneumoniae and also to non-typeable $H$. Influenzae. Such cost-effectiveness analysis based this assumption on the study made on PCV11 by Prymula [16]. However, this study did not use PCV10, used a $3+1$ immunization schedule, and represented only a subset of the most severe cases of AOM with a higher proportion of bacterial cases.

A recent study showed PCV10 to have considerably less impact on all cause AOM in a controlled environment particularly when used in a $2+1$ schedule [44]. By contrast, PCV13 is similarly effective in 3-dose and 4-dose schedules versus AOM [45]. In addition, a recent randomized trial of NP carriage of NTHi comparing PCV7 to PCV10 found no effect of PCV10 in reducing NTHi carriage. Therefore, it is unlikely that any proposed non-pneumococcal benefits will be realized with PCV10 [46]. Furthermore, the regulatory approval issued by the INVIMA and the European Medicines Agency points out that PCV10 is indicated for preventing diseases produced by the serotypes included in the pneumococcal vaccine [47].

Results from the Clinical Otitis Media and Pneumonia Study (COMPAS) with PCV10 could not provide definitive evidence on how the marketed formulation can impact all-cause otitis media in a Latin American setting, because they had a lower than expected number of AOM cases [23].

Based on pneumococcal effectiveness and serotype distribution locally, PCV13 is cost-saving versus PCV10 in regards to preventing pneumococcal disease due to all causes, preventing mortality and obtaining LYG, which leads to lower costs of care.

The main strength in this study is the local information which helps to determine the epidemiological parameters for Colombia in regards to the diseases of interest $[10,11,13,15,17,19]$. Likewise, the costs of the medical treatments are based on a national third-party payer, based on what really got paid to hospitals for the care of patients. There was no underreporting of the costs information (since it is the universe of the data base of what was paid by the insurer). The adjustment of the effectiveness of both vaccines based on the pneumococcus serotypes circulating in Colombia between 2009 and 2013 permits an updated analysis. Finally, this study includes information on the herd effect of $\mathrm{PCV} 7 \mathrm{ob}-$ served in children [20], assuming that such effect is similar for both vaccines.

The main weakness of this study is we do not have information from a head to head clinical trial between PCV13 and PCV10. Similarly, results of the COMPAS [22] study are difficult to compare because the average of follow up was 23 months, compared to four and a half years of the Northern California Kaiser Permanente Vaccine Study [5]. It could affect the results of the first one trial because the follow up was 31 months lesser than Kaiser Study, but is the best information source available about PCV10 effectiveness. In the same direction, lack of inclusion of a herd effect for children $>5$ years of age and adults underestimates the full potential impact of the vaccines, in particular the additional benefit of PCV13, because serotypes 3, $6 \mathrm{~A}$ and 19A cause pneumococcal disease in older adults.

Likewise, because the data on the prevalence of disease was taken from official records, some underreporting could have taken place, since the information depends on whether or not the physician used the correct diagnosis code. In the same way, the burden of diseases by pneumonia could have been underestimated, because we just considered cases of radiologically-confirmed pneumonia.

This study did not evaluate aftermath generated by any of the diseases, this is why the quality-adjusted life years was not determined. It must be emphasized that in terms of prevention of death due to all causes PCV13 was dominant over PCV10. Further, PCV13 prevented more cases of disease, including meningitis, and therefore would be expected to provide greater reduction in LYG and thus remain dominant in analysis.

\section{Conclusion}

PCV13 and PCV10 are better cost-effectiveness alternatives compared to no vaccination. PCV13 is dominant over PCV10 since it prevents more deaths, generates more LYG and the expected costs are lower (ICER PCV10 vs. PCV13: US\$ -417.53). 


\section{Competing interests}

This research was sponsored by Pfizer, Colombia. Researchers declare our full independence of the contract and we are solely responsible for methods, results and concepts raised in this paper.

\section{Authors' contribution}

JEO developed a systematic review and identified the epidemiologic information and treatment costs in Colombia. JJO developed the economic model. Both authors read and approved the final manuscript.

\section{Acknowledgements}

To María Patricia Arbeláez Mejía, MD, PhD, Dean of School of Public Health of Universidad de Antioquia, who reviewed and approved the manuscript. To Sura EPS, a health insurance Colombian company which provided us the data for hospitalization costs of patients with pneumonia and IPD.

\section{Author details}

'HEMO Group Carrera 25A N 1 A Sur-45, piso 5.Torre Médica El Tesoro Medellín, Medellín, Colombia. ${ }^{2}$ CES University, Medellín, Colombia.

Received: 18 June 2014 Accepted: 17 March 2015

Published online: 10 April 2015

\section{References}

1. UNICEF/WHO. Pneumonia: the forgotten killer of children. Geneva: World Health Organization; 2006.

2. United Nations. 2015 Millennium Development Goals. [Internet] Available in: https://www.invima.gov.co/images/pdf/salasespecializadas/Sala_Especializada_ de_Medicamentos/acta2011/ACTA_No_12_DE_2011.pdf (accessed May, 2012).

3. Claeson M, Gillespie D, Mshinda $\bar{H}$, Troedsson H, Victora CG. Bellagio Study Group on Child Survival Knowledge into action for child survival. Lancet. 2003;362(9380):323-7.

4. Black SB, Shinefield HR, Fireman B, Lewis E, Ray P, Hansen JR, et al. Efficacy, safety and immunogenicity of heptavalent pneumococcal conjugate vaccine in children Northern California Kaiser Permanente Vaccine Study Center Group. Pediatr Infect Dis J. 2000;19(3):187-95.

5. Black SB, Shinefield HR, Ling S, Hansen J, Fireman B, et al. Effectiveness of heptavalent pneumococcal conjugate vaccine in children younger than five years of age for prevention of pneumonia. Pediatr Infect Dis J. 2002;21(9):810-5.

6. Pavia M, Bianco A, Nobile CG, Marinelli P, Angelillo IF. Efficacy of pneumococcal vaccination in children younger than 24 months: a metaanalysis. Pediatrics. 2009;123(6):e1103-10.

7. Sabin Institute. The burden of pneumococcal disease and cost-effectiveness of a pneumococcal vaccine in Latin America and the Caribbean. A review of the evidence and a preliminary economic analysis, 2007. [Internet] Available in: http://www.ispch.cl/sites/default/files/document1.pdf (accessed Sep, 2014).

8. Giachetto G, Telechea H, Speranza N, Giglio N, Cané A, Pírez MC, et al. Costo-efectividad de la vacunación universal antineumocócica en Uruguay. Rev Panam Salud Publica. 2010;28(2):92-9.

9. DANE - Departamento Administrativo Nacional de Estadística. Proyecciones nacionales y departamentales de población 2005 - 2020: Estudios postcensales. Bogotá D.C: DANE, Centro Andino de Altos Estudios CANDANE; 2010.

10. Instituto de Vigilancia de Medicamentos y Alimentos - INVIMA. Ministerio de la Protección Social. Comisión Revisora: Sala Especializada de Medicamentos y Productos Biológicos. Acta No. 12 de 2011. Sesión ordinaria. 30 de marzo de 2011; pp.: 16-7. [Internet] Available in: http://web. invima.gov.co/portal/documents/portal/documents/root/SALAS\%20ESPECIA LIZADAS/2011_biologicos/ACTA\%20No\%2012\%20DE\%202011.pdf (accessed July, 2012).

11. Instituto Nacional de Salud. Distribución de los tipos capsulares de Streptococcus pneumoniae por año de aislamiento ( $<5$ años). [Internet]. Available in http:// www.ins.gov.co/Noticias/SiteAssets/Paginas/SIREVA-IIColombia-2003-2012/SIREVA \%2011\%20Colombia\%202003-2012.pdf Accessed Sept, 2014.

12. WHO. Making choices in health: WHO guide to cost-effectiveness analysis. Tan-Torres T, Baltussen R, Adam T, Hutubessy R, Acharya A, Evans DB, Murray CJ (Eds). World Health Organization: Geneva, 2003.

13. Benavides JA, Ovalle OO, Salvador GR, Gray S, Isaacman D, Rodgers GL. Population-based surveillance for invasive pneumococcal disease and pneumonia in infants and young children in Bogotá, Colombia. Vaccine. 2012;30(40):5886-92.
14. World Health Organization Pneumonia Vaccine Trial Investigator's Group. Standardization of interpretation of chest radiographs for the diagnosis of pneumonia in children. Geneva: Department of vaccines and biological World Health Organization; 2001.

15. Alcaldía de Medellín. Situación de salud en Medellín, Indicadores Básicos 2009. Medellín: Secretaría de Salud de Medellín; 2010.

16. Prymula R, Peeters P, Chrobok V, Kriz P, Novakoka E, Kaliskova E, et al. Pneumococcal capsular polysaccharides conjugated to protein D for prevention of acute otitis media caused by both Streptococcus pneumoniae and non-typable Haemophilus influenzae: a randomised double-blind efficacy study. Lancet. 2006;367:740-8.

17. Sierra A, Lopez P, Zapata MA, Vanegas B, Castrejon MM, Deantonio R, et al. Non-typeable Haemophilus influenzae and Streptococcus pneumoniae as primary causes of acute otitis media in colombian children: a prospective study. BMC Infect Dis. 2011;11:4.

18. Castañeda-Orjuela C, Alvis-Guzmán N, Velandia-González M, De la HozRestrepo F. Cost-effectiveness of Pneumococcal conjugate vaccines of 7, 10, and 13 valences in Colombian children. Vaccine. 2012;30:1936-43.

19. Departamento Administrativo Nacional de Estadísticas. Cuadro 1. Nacimientos por área de ocurrencia y sexo, según grupos de edad de la madre, total nacional, año 2009. [Internet] Available in: http://www.dane. gov.co/index.php/esp/poblacion-y-demografia/nacimientos-ydefunciones/ 118-demograficas/estadisticas-vitales/2882-nacimientos-2009-preliminar (accessed May, 2012).

20. Poheling KA, Talbot TR, Griffin MR, Craig AS, Whitney CG, Zell E, et al. Invasive pneumococcal disease among infants before and after introduction of pneumococcal conjugate vaccine. JAMA. 2006;295(14):1668-74.

21. Hansen J, Black S, Shinenfield H, Cherian T, Benson J, Fireman B, et al. Effectiveness of heptavalent pneumococcal conjugate vaccine in children younger than 5 years of age for prevention of pneumonia: updated analysis using World Health Organization standardized interpretation of chest radiographs. Pediatr Infect Dis J. 2006;25:779-81.

22. Tregnaghi MW, Sáez-Llorens X, López P, Abate H, Smith E, Pósleman A, et al. Efficacy of pneumococcal nontypable Haemophilus influenza protein D conjugate vaccine (PHiD-CV) in young Latin American children: A doubleblind randomized controlled trial. PLOS Med. 2014;11(6):e1001657.

23. Ben-Shimol S, Givon-Lavi N, Leibovitz E, Raiz S, Greenberg D, Dagan R. Near elimination of otitis media caused by the PCV13 serotypes in Southern Israel shortly after sequential introduction of PCV7/PCV13. Clin Infect Dis. 2014;59(12):1724-32.

24. Pan American Health Organization. Expanded Program of Immunization Vaccine Prices for year 2014. [Internet] Available in: www.paho.org (accessed Sept, 2014).

25. Departamento Administrativo Nacional de Estadísticas. Variaciones porcentuales de Índice de Precios al Consumidor (IPC), actualizado a abril de 2012. [Internet] Available in: http://www.dane.gov.co/index.php/indices-deprecios-y-costos/indice-deprecios-al-consumidor-ipc (accessed May, 2012).

26. Hernández P, Hernández S. Otitis media aguda. [Internet] Available in: http://www.aibarra.org/Apuntes/criticos/Guias/Trauma-ojos-orl/ Otitis_media_aguda.pdf (accessed May, 2012).

27. Peñaranda A. Otitis media aguda. Rev Med Clin COINDES. 2009;20(4):427-34.

28. de Hacienda M, Público C, de Salud M. Decreto 2423 de 1996, por el cual se determina la nomenclatura y clasificación de los procedimientos médicos quirúrgicos y hospitalarios del Manual Tarifario y se dictan otras disposiciones. Bogotá D.C.: Congreso de la República de Colombia; 1996.

29. World Health Organization. CHOosing Interventions that are Cost Effective (WHO-CHOICE). [Internet] Available in: http://www.who.int/choice/costs/ CER_levels/en/index.html (accessed June, 2012).

30. Ministerio de Protección Social. Acuerdo 335 de 2006, por el cual se asignan recursos de la Subcuenta de Promoción del Fondo de Solidaridad y Garantía (Fosyga) para el fortalecimiento de programas prioritarios de salud pública y se dictan otras disposiciones. Bogotá: Ministerio de Protección Social. Consejo Nacional de Seguridad Social en Salud.

31. Strutton DR, Farkouh RA, Earnshaw SR, Hwang S, Theidel U, Kontodimas S, et al. Cost-effectiveness of 13-valent pneumococcal conjugate vaccine: Germnay, Greece, and The Netherlands. J Infect. 2012;64(1):54-67.

32. Newall AT, Creighton P, Philp DJ, Wod JG, Maclntyre CR. The potential cost-effectiveness of infant pneumococcal vaccines in Australia. Vaccine. 2011;29(45):8077-85.

33. Earnshaw SR, McDade CL, Farkohuh RA ZG, Strutton D. BMC Infect Dis. 2012;12(1):101 [Epub ahead of print].

34. Díez-Domingo J, Ridao-López M, Gutiérrez-Gimeno MV, Puig-Barberá J, Lluch-Rodrigo JA, Pastor-Villalba E. Pharmacoeconomic assessment of 
implementing a universal PCV-13 vaccination programme in the Valencian public health system (Spain). Vaccine. 2011;29(52):9640-8.

35. Rubine JL, McGarry L, Strutton DR, Klugman KP, Pelton SI, Gilmore KE, et al. Public health economic impact of the 13-valent pneumococcal conjugate vaccine (PCV13) in the United States. Vaccine. 2010;28(48):7634-43.

36. Boccalini S, Azzari C, Resti M, Valleriani C, Cortimiglia M, Tiscione E, et al. Economic and clinical evaluation of a catch-up dose of 13-valent pneumococcal conjugate vaccine in children already immunized with three doses of the 7valent vaccine in Italy. Vaccine. 2011;29(51):9521-8.

37. Muciño-Ortega E, Mould-Quevedo JF, Farkouh R, Strutton D. Evaluación económica de un programa de inmunización infantil en México basado en la vacuna neumocócica conjugada 13-valente. Value Health. 2011;14(5 Suppl 1):S65-70.

38. Blank PR, Szucs TD. Cost-effectiveness of 13-valent pneumococcal conjugate vaccine in Switzerland. Vaccine. 2012;30(28):4267-75.

39. Wu DB, Chang CJ, Huang YC, Wen YW, Wu CL, Fann CS. Cost-effectiveness analysis of pneumococcal conjugate vaccine in Taiwan: a transmission dynamic modeling approach. Value Health. 2012;15(1 Suppl):S15-9.

40. Hortal M, Estevan M, Laurani H, Iraola I, Meny M, Paysandú/Salto Study Group. Hospitalized children with pneumonia in Uruguay: Pre and post introduction of 7 and 13-valent pneumococcal conjugated vaccines into the National Immunization Program. Vaccine. 2012;30(33):4934-8.

41. Urueña A, Pippo T, Betelu MS, Virgilio F, Giglio N, Gentile A, et al. Costeffectiveness analysis of the 10- and 13-valent pneumococcal conjugate vaccines in Argentina. Vaccine. 2011;29(31):4963-72.

42. Knerer G, Ismalia A, Pearce D. Health and economic impact of PHiD-CV in Canada and the UK: a Markov modeling exercise. J Med Econ. 2012:15(1):61-76

43. By A, Sobocky P, Forsgren A, Silfverdal SA. Comparing health outcomes and costs of general vaccination with pneumococcal conjugate vaccines in Sweden: a Markov model. Clin Ther. 2012;34(1):177-89.

44. Vesikari T, Forstén A, Seppä I, Puumalainen T, Soininen A, Lommel P, et al. Effectiveness of the 10-valent pneumococcal non-typeable Haemophilus influenza protein $\mathrm{D}$ conjugate vaccine against acute otitis media. Abstract. $52^{\text {nd }}$ ICAAC 2012. Presentation number G-1054a. [Internet]. Available in: http://www.abstractsonline.com/Plan/NiewAbstract.aspx?sKey=7cc8a70d9b35-49a7-b9c9-83b649b9db28\&cKey=6b611a96-828b-4a7e-a0592b0ff0ce1899\&mKey=\%7b6B114A1D-85A4-4054-A83B-04D8B9B8749F\%7d (accessed October, 2012).

45. Stoecker C, Hampton LM, Moore MR. 7-Valent pneumococcal conjugate vaccine and otitis media: Effectiveness of a 2-dose versus 3-dose primary series. Vaccine. 2012;30(44):6256-62.

46. van den Bergh MR, Spijkerman J, Swinnen KM, François NA, Pascal TG, Borys D, et al. Effects of the 10-valent Pneumococcal nontypeable Haemophilus influenzae Protein D-Conjugate Vaccine (PHiD-CV) on nasopharyngeal bacterial colonization in young children: a randomized controlled trial. Clin Infect Dis. 2013;56(3):e30

47. Agencia Europea de Medicamentos. Ficha técnica o resumen de las características del producto. [Internet] Available in: http://www.ema.europa. eu/docs/es_ES/document_library/EPAR_-_Product_Information/human/ 000973/WC500054346.pdf (accessed June, 2012).

\section{Submit your next manuscript to BioMed Central and take full advantage of:}

- Convenient online submission

- Thorough peer review

- No space constraints or color figure charges

- Immediate publication on acceptance

- Inclusion in PubMed, CAS, Scopus and Google Scholar

- Research which is freely available for redistribution

Submit your manuscript at www.biomedcentral.com/submit 